\title{
The Complexity of Different Types of Attitudes in Initial and Continued ICT Use
}

\author{
Ping Zhang \\ School of Information Studies, Syracuse University, Syracuse, NY. E-mail: pzhang@syr.edu \\ Heshan Sun \\ School of Information Resources and Library Science, University of Arizona, 1515 East First Street, \\ Tucson, AZ. E-mail: hsun@email.arizona.edu
}

\begin{abstract}
In the information systems (IS) field, research interest in attitude has fluctuated over the past decades given the inconsistent and inconclusive findings on attitude's effects on behavioral intention (BI) to use information and communication technology (ICT). This study addresses the conceptual, operational, and temporal dynamics of attitude that may have caused the inconsistent and inconclusive results. A longitudinal study was conducted to validate our hypotheses. The results show that: (a) The attitude that significantly influences $\mathrm{BI}$ needs to be at a particular specificity with BI on two aspects, the same evaluation target and the same evaluation time, where the time specificity can supersede the target specificity; (b) the relationships among attitudes and intention remain the same if they are measured at the same time, regardless of use stages; (c) the two types of attitudes show different long-lasting effects over time; (d) omitting important mediating factors in a research model may generate misleading messages; and (e) attitudes alone can explain a large amount of variances in BI. The results can help explain the reasons behind inconsistent findings in the literature, inspire additional research efforts, and suggest bringing attitudes back to information systems research due to their theoretical and practical importance.
\end{abstract}

\section{Introduction}

Information and communication technologies (ICT) have become one of the most important parts of organizations, businesses, and communities. Because many ICTs are designed for the purposes of supporting productivity and communication in social settings, their values can be realized only if they are accepted/adopted, used, and used continuously by intended users. Consequently, research studies on factors influencing ICT acceptance and use decisions have

Received December 19, 2008; revised March 19, 2009; accepted April 14, 2009

(C) 2009 ASIS\&T • Published online 25 June 2009 in Wiley InterScience (www.interscience.wiley.com). DOI: 10.1002/asi.21116 become one of the most prolific research areas in modern information systems (IS) literature (Agarwal \& Prasad, 1997; King \& He, 2006; Lee, Kozar, \& Larsen, 2003; Sun \& Zhang, 2006; Venkatesh, Morris, Davis, \& Davis, 2003; Wixom \& Todd, 2005). Such studies are largely influenced by theories in social psychology.

Bhattacherjee and Sanford (2006) identified two dominant theoretical foundations on ICT acceptance and use research in the IS literature that have been influential during the past decades: (a) the theory of reasoned action (TRA) and the theory of planned behavior (TPB; Ajzen, 1991a; Ajzen \& Fishbein, 1980), and (b) innovation diffusion theory (IDT; Rogers, 1995). Bhattacherjee and Sanford (2006) then provided another theoretical foundation, the dual-process theory of persuasion, such as the elaboration likelihood model (ELM; Petty \& Cacioppo, 1986; Petty \& Wegener, 1999). These perspectives provide different ways of explaining the processes, through which individual users formulate their ICT acceptance, use, and continued use decisions. Important concepts related to the decisions are beliefs, attitudes, BIs, and actual use behavior. For a detailed description of the differences among these perspectives, please see Bhattacherjee and Sanford (2006).

Despite the theoretical importance of attitude, as depicted directly by two of the three dominant theoretical foundations mentioned above (TRA/TPB and ELM), attitude has not achieved consistent attention in IS research on ICT acceptance and continued use. Research interest in attitude has fluctuated over the decades, largely because of the fact that empirical studies have found inconsistent and inconclusive results on attitude's effect on BI and behavior. The results lead researchers to believe that attitude is not an important concept in technology acceptance. For example, observing that attitude seems to not have a significant impact on intention to use in the original Technology Acceptance Model (TAM; Davis, Bagozzi, \& Warshaw, 1989), a good number of studies on technology acceptance used a simplified TAM 
model, excluding attitude from the original model. Based on a survey of the literature, attitude toward using technology is claimed not to be a direct determinant of intention and, thus, is excluded from the Unified Theory of Acceptance and Use of Technology (UTAUT), a model that attempts to synthesize prior ICT acceptance research (Venkatesh et al., 2003). Such a conclusion, if not treated carefully, can have significant implications to theory, research, and practice. Attitude is an important concept in social judgments and behaviors and, thus, is one of the most important concepts in social psychology. A concluding statement that attitude is not a significant antecedent of intention could mean that the theories of reasoned action and planned behavior and the elaboration likelihood model may not apply to ICT acceptance and use research as they would to other social contexts. This can be discouraging and, thus, diminish research efforts in finding the gaps and holes in existing research. At the practical level, such a concluding statement can influence ICT stakeholders' strategic investment on their efforts in improving users' acceptance, use, and continued use of ICT. Therefore, a systematic study on attitude is highly needed before we make or accept such a conclusion.

Careful reexaminations of the IS literature and attitude theories in social psychology can reveal serious concerns in ICT acceptance and use studies that include attitudes. It was posited that both conceptualization and operationalization of attitude in the IS literature might have induced the inconsistent and inconclusive results (Zhang, Aikman, \& Sun, 2008). Some studies confused the concept of attitude toward using ICT (namely, attitude toward behavior, ATB) with attitude toward ICT itself (namely, attitude toward object, ATO; Ajzen \& Fishbein, 1980, 2005; Eagly \& Chaiken, 1998; Forgas, 2000). Inclusive and inconsistent findings may also be the results of differences in operationalization and measurements (Zhang et al., 2008).

Attitudes and their effects on technology acceptance may become even more complex if they are considered across time. This is suggested by the principle of compatibility for a behavior that concerns three levels of specificity: a single behavior can be viewed as involving an action directed at a target, performed in a given context, and at a certain point in time (Ajzen \& Fishbein, 2005). Yet, few studies have addressed this temporal issue in studying attitudes in the ICT context.

The objective of this current study is, thus, to continue exploring the nature of the two types of attitudes and their relationships with BI with regard to the temporal aspect (that is, across time), such as from initial to continued use of ICT. Attitude theories suggest that attitudes can be considered new judgments that are influenced by initial judgments (which may become the stored initial judgments), external information, and prior knowledge (Albarracin, Zanna, Johnson, \& Kumkale, 2005). During the initial ICT use stage, users form their initial attitudes. During the continued ICT use stage, the new attitudes can be influenced by the initial attitudes as well as by additional information the users continuously acquire about the ICT, among other factors. Attitude theories state that the relationships among attitudes and intention remain the same. We speculate that this is true in the ICT context as well if these factors are treated appropriately; yet, the findings may be different if these factors are handled differently. To be focused, we consider only attitudes and BIs as the main variables in our study. Other factors and relationships in ICT acceptance and use have been well covered in the literature and can be added later once our understanding of attitudes becomes clearer. To strengthen the conceptual, operational, and temporal clarification on attitudes, this study addresses the following research questions:

RQ1. Do the relationships among ATO, ATB and BI remain the same at the initial and continued ICT use stages respectively?

RQ2. Do users' attitudes and BIs formed during initial use influence their attitudes and BIs during continued use?

This research holds several contributions to the field. To the best of our knowledge, few studies have considered the two types of attitudes together in the same study to distinguish them from each other, with a few exceptions (Hartwick \& Barki, 1994; Wixom \& Todd, 2005; Zhang et al., 2008). Moreover, few studies take a longitudinal perspective to studying the dynamic relationships among attitudes and intention across different ICT use stages, with one exception, which, however, focused merely on attitude toward object (Hartwick \& Barki, 1994).

In this sense, this study can offer insights into the attitude concepts and their longitudinal nature. Such insights can have theoretical, research, and practical values. Theoretically, the insights help reestablish the important position of attitudes in IS research and prescribe potential pitfalls of yielding misleading findings. As for research, the findings shed light on the complexity of attitudes, on cautions for future empirical research on attitudes including the measurements, and on directions for future research efforts. Practically, findings from this study can help practitioners manage ICT design and implementation, as well as identify appropriate strategies to influence users' different attitudes at different stages of ICT use.

In the next section, we provide a systematic review of the IS literature on attitude research. Such a review is lacking in the literature but can provide a good understanding of the status of attitude studies in the ICT context. Although we also take temporal aspect into consideration in the literature review, as can be seen, few studies focused on the temporal aspect of attitude in the ICT context. Then we conceptualize attitude concepts and their impacts on BI at different ICT use stages. A theoretical model with corresponding hypotheses is developed. These hypotheses are then empirically validated through a longitudinal study. Finally, we discuss findings and implications.

\section{Literature Review on Attitudes in the ICT Context}

Attitude toward object (ATO) is defined as "a psychological tendency that is expressed by evaluating a particular entity 
with some degree of favor or disfavor" (Eagly \& Chaiken, 1998) or, as a combination of evaluative judgments about an object (Crites, Fabrigar, \& Petty, 1994). Attitude toward behavior (ATB) is defined as “an individual's positive or negative feelings (evaluative affect) about performing the target behavior" (Fishbein \& Ajzen, 1975). A closely related concept is BI, which refers to the measure of the strength of one's intention to perform a specified behavior (Fishbein \& Ajzen, 1975). Attitude theories in social psychology show that these two types of attitudes - ATO and ATB - are conceptually different and have different effects on BI. According to attitude theories, ATB is a strong predictor of BI, while the impact of ATO on intention is fully mediated by ATB (Fishbein \& Ajzen, 1975).

Attitude, especially attitude toward behavior, is primarily introduced through TRA (Ajzen \& Fishbein, 1980; Fishbein \& Ajzen, 1975) and TPB (Ajzen, 1985, 1991). TRA defines beliefs as cognitions about the probability that an object or event is associated with a given attribute, and behaviors as the overt actions of an individual (Fishbein \& Ajzen, 1975). TRA then posits that behavior is driven by BI, while intention is dependent on, or a function of, an attitude toward behavior and subjective norms surrounding the performance of the behavior. TPB (Ajzen, 1991) extends TRA and posits that behavioral beliefs produce a favorable or unfavorable attitude toward behavior; in combination, attitude toward behavior, subjective norms, and control beliefs (about behavioral control) lead to the formation of BI. In a recent effort to clarify the roles of attitudes in behavior, Ajzen and Fishbein (2005) re-stated the differences between attitude toward object and toward behavior that are both theoretically and empirically established.

In the past several decades, TRA and TPB have greatly influenced the IS field on technology acceptance research, from the formation of the famous TAM (Davis, 1989), to a number of alternative models, to a recent attempt at a unified theory of technology acceptance (Venkatesh et al., 2003), and to several studies on perfecting the models by considering moderating and other factors (e.g., Schepers \& Wetzels, 2007; Sun \& Zhang, 2006). Attitude is considered in some of the studies as an antecedent to BI.

We examined both ATO and ATB in the IS literature and found that the predictive importance of attitude to BIs varied with reasons that can be conceptual, operational, or contextual, among others. Appendix A provides a summary of the empirical studies containing attitudes in the IS literature.

At the conceptualization level, for example, on the roles of attitude toward ICT (ATO), Jackson and colleagues studied attitude toward a new information system and found that it did not have a direct effect on BI (Jackson, Chow, \& Leitch, 1997). Lin and Bhattacherjee (in press), on the other hand, found a significant direct impact of ATO on BI. As for ATB's effect on BI or behavior, Limayen and Hirt treated attitude as affect, yet measured it in similar ways as ATB was measured in some other studies (Limayem \& Hirt, 2003). They found that its effect on BI is non-significant (Limayem \& Hirt, 2003). Thompson and colleagues, on other hand, defined attitude as affect toward PC use and found that ATB->BI is either non-significant (Thompson, Higgins, \& Howell, 1991) or ATB-> Behavior is stronger for inexperienced users than experienced users (Thompson \& Higgins, 1994). Also, we were not surprised to learn that there are a great number of studies that found the significant ATB->BI link, as suggested by TRA/TPB (e.g., Agarwal \& Prasad, 1999; Bhattacherjee \& Premkumar, 2004; Brown, Fuller, \& Vician, 2004; Chau \& Hu, 2001; D. A. Harrison, Mykytyn, \& Riemenschneider, 1997; Karahanna, Straub, \& Chervany, 1999; Malhotra \& Galletta, 2005; Mathieson, 1991; Moon \& Kim, 2001; Taylor \& Todd, 1995; Wixom \& Todd, 2005).

Barki and Hartwick's work is worth special mention (Barki \& Hartwick, 1989, 1994; Hartwick \& Barki, 1994). They considered both ATO (a psychological state reflecting the affective or evaluative feelings concerning a new system) and ATB (attitude concerning use) in the study. ATO is found to be an antecedent to ATB at the post-implementation stage. ATB is found to be a significant antecedent to intention to use the system at both the pre-implementation and the post-implementation stage, while ATB's effect on BI is much stronger during post-implementation. From a longitudinal perspective, they found that ATO at pre-implementation stage influences ATO at post-implementation stage. However, they did not examine the relationship between the ATBs during different stages. They also did not examine the cross-type effects among ATOs and ATBs across time. For example, it is unknown if ATO at pre-implementation would influence ATB at post-implementation (Hartwick \& Barki, 1994).

At the operationalization level, the measures for attitude are also varied. Some studies conceptualized attitude as ATO, yet measured it based on Ajzen and Fishbein's (Ajzen \& Fishbein, 1980) original recommendations for ATB (e.g., Jackson et al., 1997). Some measured "global" attitudes (i.e., overall evaluations), while others measured the information base of the attitudes (e.g., the underlying reasons for the global attitude). For example, perceived ease of use and perceived usefulness were considered as attitude measures in some studies (e.g., Harrison \& Rainer, 1992; Sambamurthy \& Chin, 1994). Yet in TAM and other similar models, these two are the cognitive antecedents (i.e., cognitive information base) of attitude. Some studies measured attitude with a mix of ATO and ATB (e.g., Thompson \& Higgins, 1994). Also, the measures covered different or unbalanced components/bases of attitude, including instrumental (e.g., "beneficial," "useful," "valuable"), experiential ("unpleasant," "enjoyable,"), or something at a more general level ("good/bad," "negative/positive," "favorable/unfavorable").

The implied context in which attitudes toward ICT were measured is also varied. Some studies assessed attitude toward general ICT (or ICT use) in which context is not considered (e.g., Brown et al., 2004; Mathieson, 1991); others studied a specific target ICT within a specific context (e.g., Chau \& Hu, 2001; Karahanna et al., 1999).

Other researchers have noted the misconception of the attitude construct as well. For instance, Wixom and Todd (2005) stated explicitly the differences between ATO and 
ATB, considered satisfaction with an IS as ATO, and included both satisfaction and ATB in their research model. Since we found no other ICT-related studies that considered both ATO and ATB together, and no ICT studies that considered longitudinal effects of attitudes, we decided to guide our discovery by attitude theory-based speculations on the roles of attitudes during different ICT use stages, while keeping an open mind so that we could explore the dynamic nature of attitudes.

\section{Theoretical Development}

\section{Two Types of Attitudes}

The two types of attitudes have different functions regarding behavior and BI. In particular, ATB has been stated to be a much better predictor of BI and behavior than ATO (Ajzen \& Fishbein, 1980, 2005). This can be explained by the principle of compatibility (Eagly \& Chaiken, 1998; Fishbein \& Ajzen, 1975). The principle of compatibility for a behavior concerns three levels of specificity: a single behavior can be viewed as involving an action directed at a target, performed in a given context, at a certain point in time (Ajzen \& Fishbein, 2005). Generally, for an attitude to be predictive of behavior, the attitude must be assessed at the same level of specificity. That is, the attitude being assessed must be as broad as the behavior in question. It follows then that a BI toward using something (e.g., an ICT) would be best predicted by an attitude measure of behavior regarding that object, rather than an attitude measure of the object itself, which by definition is being assessed at a different level of specificity. Further, Eagly and Chaiken pointed out that although there are two broad theories of attitudes that are generally examined separately (i.e., either attitude toward the object or attitude toward the behavior), it might be useful to examine both together to get a good prediction of behavior. For example, once an attitude toward an object has been activated, there are likely still many options of appropriate behaviors from which to choose. If a link is established between an ATO and an ATB (as a possible behavioral choice), then once an ATO has been activated, the ATB should also be activated; this leads to a good prediction of behavior (Eagly \& Chaiken, 1998).

The specific relationships - that ATO predicts ATB, ATB predicts BI, and ATO does not have a direct effect on BIshould hold true if they are measured at the same time, regardless of ICT use stages. Again, this can be explained by the principle of compatibility at the target, context, and time specificities. At any stage of use, one's attitude toward an ICT activates his/her attitude toward using the ICT. Both are about attitudes, although on different "targets": one is an object; the other is an action on the object. But attitude toward ICT does not necessarily influence one's intention to use the ICT: not only are the evaluation "targets" different (one is about the object, the other behavior), but the mental evaluations are different as well-one is intention and one is attitude. Attitude toward using ICT is a better predictor of using ICT because they are both about use - a behavior. Thus, we anticipate that the relationships among ATO, ATB, and BI should hold true for both the initial and continued ICT use stages. To test such relationships, the following hypotheses are formed. $\mathrm{H} 3$ is stated in such a way that we hope to prove that it does not hold true, which would support our theoretical reasoning.

H1: Attitude toward an ICT (ATO) has a positive relation with attitude toward using it (ATB), at both initial (H1a) and continued use stages (H1b).

$\mathrm{H} 2$ : Attitude toward using an ICT (ATB) has a positive relation with BI to use the ICT, at both initial (H2a) and continued use stages $(\mathrm{H} 2 \mathrm{~b})$.

H3: Attitude toward an ICT (ATO) has a direct effect on BI to use the ICT $(\mathrm{BI})$, at both the initial $(\mathrm{H} 3 \mathrm{a})$ and continued use $(\mathrm{H} 3 \mathrm{~b})$ stages.

\section{The Longitudinal Nature of Attitudes}

User judgments and evaluations are not formed from scratch. Instead, prior judgments and evaluations serve as the "anchor" for the user and the new piece of information serves as adjustments (Kim \& Malhotra, 2005). Similar theoretical arguments can be found in the ELM as well (Petty \& Cacioppo, 1986; Petty \& Wegener, 1999). According to ELM, attitude formation and change may occur by two routes of influence: central route and peripheral route. They differ in the amount of thoughtful information processing or elaboration an individual has during the change process (Petty \& Cacioppo, 1986; Petty \& Wegener, 1999). The peripheral route involves less cognitive effort, less deep or arduous thinking. It relies mainly on information as heuristic cues, such as familiarity of the attitude object or credibility of the information source. The elaboration process via peripheral route is considered shallow or low (Wegener \& Carlston, 2005). Such a process may involve mere association (such as classical conditional-the attitude object is temporally paired with another positively or negatively valenced object or experience), or inferential approaches (such that people briefly consider some piece of information but use it as a relatively simple way to determine whether a positive or negative evaluation is appropriate, without taking the time or effort that would be involved in more extensive processing of other available information; Wegener \& Carlston, 2005). The central route, on the other hand, requires the person to think critically about the attitude object. The elaboration process is moderate to high in that scrutiny of an attitude object goes beyond memorization of presented information. Such elaboration can be captured as follows: by effortful processing, careful thinking, attending to any presented information, attempting to access relevant information from both external (message) and internal (knowledge) sources, comparing information with background knowledge and standards (including one's previous evaluations of the objects), and drawing conclusions about the merits of the attitude object or recommendation, as well as a derivation of an overall evaluation that combines the outputs of these efforts (Petty \& Cacioppo, 1986; Petty \& Wegener, 1999). Therefore, 
in both central and peripheral routes, users refer to their prior knowledge or experience with the object (Petty \& Cacioppo, 1986; Petty \& Wegener, 1999). The ELM has been successfully applied to studying user judgments and evaluations of information systems (Bhattacherjee \& Sanford, 2006).

Furthermore, considering again the principle of compatibility, the evaluations of the same object at different times would be more correlated than the evaluations of the different objects at different times. That is, ATO1 and ATO2, although at different times, are both about attitude toward the same target ICT. Similarly, ATB1 and ATB2 are both about attitudes toward using the same target ICT at different time. The principle of compatibility should project a correlation between ATO1 and ATO2, and, therefore, this is true for ATB1 and ATB2. In contrast, the correlation between ATO1 and ATB2, and the correlation between ATB1 and ATO2 should be low because of their low conceptual compatibility. In fact, we anticipate that ATO1 and ATB2 are unlikely to be correlated, nor are ATO2 and ATB1. This is because the evaluations (various attitudes) have come across two aspects of differences: the evaluation target and the evaluation time.

Therefore, the following hypotheses are developed. H6 and $\mathrm{H} 7$ are stated as the opposite of our expectations.

H4: Attitude toward the ICT that is formed during initial use correlates with attitude toward the ICT during the continued use (ATO1->ATO2).

H5: Attitude toward using the ICT that is formed during initial use correlates with attitude toward using the ICT during the continued use (ATB1->ATB2).

H6: Attitude toward the ICT that is formed during initial use correlates with attitude toward using the ICT during the continued use (ATO1->ATB2).

H7: Attitude toward using the ICT that is formed during initial use correlates with attitude toward the ICT during the continued use (ATB1->ATO2).

\section{The Role of Early BI}

Attitude studies also suggest that prior behavior can have various effects on current attitudes and BI. Past behaviors, along with attitudes toward the behavior and subjective norms, predict BIs even when those past behaviors are not well-learned (Ouellette \& Wood, 1998). In a study for travelmode choices, decisions can be affected by interventions that produce change in attitudes, and past behavior contributes to the prediction of later behavior when circumstances remain relatively stable (Bamberg, Ajzen, \& Schmidt, 2003). Kim and Malhotra (2005) also found that prior behavior intention can influence current behavior intention through the sequential updating mechanism.

In our case, we focus on the case where the initial ICT use and continued ICT use situations are relatively stable with little inventions introduced in between the two stages. We, thus, expect that past BI (which is a predictor of behavior) will also predict current BI. More specifically, past BI serves as an "anchor" of the current BI (Kim \& Malhotra, 2005). This

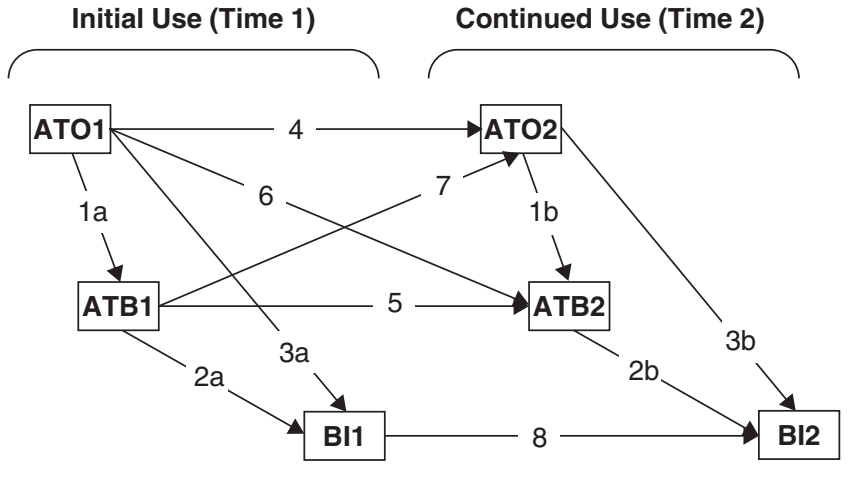

FIG. 1. Theoretical Model ATO: attitude toward the target ICT ATB: attitude toward using the target ICT BI: behavioral intention of using the target ICT.

means that past behavior influences current BI and that they may not necessarily be the same. This leads to the following hypothesis between BIs at two different use stages.

H8: BI during initial ICT use positively correlates with BI during the continued ICT use (BI1->BI2).

Figure 1 depicts a theoretical model that summarizes the hypotheses. The model spans two use stages of the target ICT: Time 1 is about initial use of the target ICT; Time 2 is about continued use of the target ICT. Hypotheses 1-3 indicate the relationships within a particular use stage; thus, they address RQ1. Hypotheses 4-7 are about the impacts of early attitudes on later attitudes; Hypothesis 8 is about the role of BI from initial use on to the continued use stage. These hypotheses address RQ2.

It is worth noting the differences between our research model and Hartwick and Barki's study (1994) because both studies involve two types of attitudes and both studies were conducted in a longitudinal setting. First of all, our two stages are about ICT use (one is initial use and one is continued use), while Hartwick and Barki's study was concerned with pre-implementation (not a use situation) and post-implementation (a continued use situation). Second, our study considers all possible relationships among ATO, ATB, and BI across time (11 hypotheses), while Hartwick and Barki's considered only ATO1->ATO2 (our H4), ATO2 ->ATB2 (H1b), ATB1->BI1 (H2a), ATB2->BI2 (H2b), and ATO2->BI2 (H3b). In particular, the longitudinal effect in Harwick and Barki's study is only limited to ATO1->ATO2. Together, our model can depict a much clearer picture of longterm influencing effects of ATO, ATB, and BI during initial use stage on ATO, ATB, and BI during continued use stage.

\section{Research Method}

\section{Study Setting and Target ICT}

This study tests the research hypotheses in a mandatory ICT use context. It is worth mentioning the appropriateness of studying ICT use intention in a mandatory context. It was recognized that some may have a perception that in 
mandatory settings, there is little variance in BI and actual use (Hartwick \& Barki, 1994). This may seem true if BI is measured by a "yes/no" nominal category. Yet, existing research shows that BI can vary substantially even in mandatory use environments (Hartwick \& Barki, 1994). In mandatory settings, people can still choose to use a system at different levels and to different extents. They can have various intentions regarding how much and to what extent they use the system in the future. In short, even when people perceive their use of the system is organizationally mandatory, BIs still vary because some users do not want to obey the mandates (Venkatesh \& Davis, 2000). While existing studies have paid attention to voluntary use (Hartwick \& Barki, 1994; Yang \& Yoo, 2004), the relevance of studying BI in a mandatory context is evidenced by initial work on the technology acceptance model, which targeted work place technology that is often either mandatory or in captive use (the users had no other alternative to complete their tasks), and by a good number of later studies (Sun \& Zhang, 2006). More research on mandatory use is of continued importance given there are still many mandatory ICT use situations, especially in organizational settings. Furthermore, existing models rooted in TRA/TPB are applicable to studying IT use in mandatory settings. TRA/TPB is aimed at understanding volitional behavior, i.e., one's behavior under control. In mandatory settings, people still have control over their behavior, although based on different considerations (Hartwick \& Barki, 1994).

The data for this study was collected as part of a larger longitudinal field study to understand college students' evaluations of a learning management system, WebCT, at a major northeastern university in the US. WebCT provides an online environment for instructors and students to share courserelated materials and conduct course-related activities and communications. WebCT is, thus, one type of ICT used in an organizational setting. WebCT, like many other ICTs, needs to be accepted and used by its intended users, students, and instructors. WebCT and student participants together can represent the general situations of ICT and its intended users in addressing research questions of technology acceptance, evaluation, and use. This makes WebCT and students well-suited for a study that examines the related issues as the ones on which we focus in this study.

The university has been using WebCT for years in both campus and distance courses. A new version, WebCT 6 (the target ICT in this study), was implemented in the Fall 2006 semester. It was significantly different from its previous version (WebCT 4) with a new look and feel, along with new concepts and functions. In many ways, WebCT 6 was a new system, and, thus, required users to have new mental models of some of its features.

For this study, we consider WebCT 6 to be used by instructors and students for supporting their teaching/learning in one class (versus using WebCT 6 as a communication tool across programs or courses, which this university does too). Only students from those classes that required WebCT 6 as a part of the teaching were invited to participate in the study. Each of those classes used several or all of the functions from the following categories: (a) sharing learning materials (syllabus, teaching notes, readings, online resources); (b) providing communications (e-mail, chat, announcements, discussions, calendar); (c) supporting learning activities (submitting assignments, grading assignments, posting/ publishing assignments for critiques/quizzes/surveys); and (d) supporting student self-management (searching within Web site, saving notes).

\section{Data Collection}

Two datasets were collected through the survey method in the Fall 2006 semester. The first dataset was collected during the 3rd and 4th weeks of the semester when students were getting settled in their classes after the adjustment period. An announcement for the survey was posted in the WebCT 6.0 homepages of 45 classes. An incentive of winning one of two drawings of $\$ 100$ cash prizes was offered for voluntary participation. A URL link directed participants to a survey Web site hosted at SurveyMonkey.com. Anyone in these classes would be able to participate by clicking the link. The second data set was collected during the 11th and 12 th weeks of the semester when the classes were close to being finished and all students should have had quite some use of WebCT 6. Participants from the first survey were sent an e-mail invitation to participate in the second survey. The incentive for participating was winning one of the two cash prizes of $\$ 150$ each. The final sample for this study comprised 120 participants who completed both surveys that are usable. Table 1 shows the demographic data of the participants. Given the length and complexity of the survey instrument and the interval of more than 7 weeks between the two surveys, we believe that there should be no carry-over effect from Survey 1 to Survey 2.

\section{Construct Measures}

Most attitude measurement techniques resulted in capturing only the affective side of the concept (Ajzen \& Fishbein,

TABLE 1. Demographic data of the participants.

\begin{tabular}{|c|c|c|}
\hline & & $\%$ \\
\hline Male & & 60.7 \\
\hline Female & & 39.3 \\
\hline Caucasian & & 64.4 \\
\hline Asian & & 20.3 \\
\hline African-American & & 5.1 \\
\hline Hispanic & & 4.2 \\
\hline Other & & 5.9 \\
\hline Undergraduate students & & 18.9 \\
\hline Masters students & & 64.0 \\
\hline \multirow[t]{2}{*}{ Doctoral students } & & 17.1 \\
\hline & Mean & $S D$ \\
\hline Age & 29.8 & 10.0 \\
\hline Year of using computers & 14.8 & 5.7 \\
\hline Year of using the Web & 9.8 & 2.8 \\
\hline
\end{tabular}


2005). Our literature review confirmed that this practice does exist in IS literature. IS research has widely accepted the attitude definition by Fishbein and Ajzen (1975) in that attitude is "an individual's positive or negative feelings (evaluative affect) about performing the target behavior" (Davis et al., 1989; Moon \& Kim, 2001; Venkatesh et al., 2003). That is, attitudes are often considered overall affective evaluations (Ajzen \& Fishbein, 1980).

The most recent theoretical understanding of the structure of attitude posits that attitude toward behavior contains instrumental (e.g., desirable-undesirable, valuable-worthless) as well as experiential (e.g., pleasant-unpleasant, interestingboring) aspects; thus, measures of attitude toward behavior should contain items representing these two subcomponents (Ajzen \& Fishbein, 2005).

Attitude toward object is "a psychological tendency that is expressed by evaluating a particular entity with some degree of favor or disfavor" (Eagly \& Chaiken, 1998) or as a combination of evaluative judgments about an object (Crites et al., 1994). It has been well established that it should be measured by general evaluative terms, such as positive/negative, good/bad, desirable/undesirable, and like/dislike (Crites et al., 1994). Incidentally, such a measure of ATO can also be considered having two dimensions after comparing the suggested items for ATB: instrumental (desirable/undesirable, and good/bad) and experiential (positive/negative and like/dislike).

The measures for BI were adopted from Wixom and Todd (2005). Appendix B lists the instrument. All constructs were measured using multiple items on 5-point Likert scales (1 for strongly disagree, 2 for somewhat disagree, 3 for neither agree nor disagree, 4 for somewhat agree, and 5 for strongly agree).

\section{Data Analysis and Results}

Data analysis consisted of two phases. The first phase was to validate the psychometric property of the instrument. The second phase was to test the hypotheses.

Partial Least Square (PLS) was used for the analysis. As a component-based structural equation modeling (SEM) technique, PLS is in essence exploratory and emphasizes explaining variances (Gefen \& Straub, 2005; Gefen, Straub, \& Boudreau, 2000). In this sense, PLS is appropriate for this research since we have new relationships and are interested in the explanatory power of the research model. Table 2 shows the descriptive statistics of the constructs' indicators.

\section{Scale Validation}

The measurement model was examined for convergent validity and discriminant validity. Convergent validity was assessed by reliability of items, composite reliability of constructs, and average variance extracted (AVE). Reliability of items was assessed by examining each item's loading on its corresponding construct. A common rule of thumb suggests that the item loading should exceed 0.70 (Barclay, Higgins, \&
TABLE 2. Descriptive statistics of the indicators of the constructs.

\begin{tabular}{lll|lll}
\hline Time 1 & Mean & $S D$ & Time 2 & Mean & $S D$ \\
\hline ATO1.1 & 3.50 & 1.06 & ATO2.1 & 3.26 & 1.17 \\
ATO1.2 & 3.49 & 1.10 & ATO2.2 & 3.30 & 1.21 \\
ATO1.3 & 3.78 & 1.07 & ATO2.3 & 3.49 & 1.19 \\
ATO1.4 & 3.81 & 1.03 & ATO2.4 & 3.47 & 1.20 \\
ATB1.1 & 3.21 & 1.07 & ATB2.1 & 3.13 & 1.13 \\
ATB1.2 & 3.79 & 1.08 & ATB2.2 & 3.87 & 1.09 \\
ATB1.3 & 3.31 & 1.07 & ATB2.3 & 3.17 & 1.05 \\
ATB1.4 & 3.42 & 1.12 & ATB2.4 & 3.16 & 1.07 \\
BI1.1 & 3.38 & 1.18 & BI2.1 & 2.94 & 1.19 \\
BI1.2 & 3.41 & 1.09 & BI2.2 & 3.16 & 1.12 \\
\hline
\end{tabular}

TABLE 3. Cross loading of indicators.

\begin{tabular}{lllllll}
\hline & ATO1 & ATB1 & BI1 & ATO2 & ATB2 & BI2 \\
\hline ATO1.1 & $\mathbf{0 . 8 9}$ & 0.68 & 0.47 & 0.57 & 0.50 & 0.43 \\
ATO1.2 & $\mathbf{0 . 9 2}$ & 0.71 & 0.56 & 0.66 & 0.57 & 0.43 \\
ATO1.3 & $\mathbf{0 . 9 3}$ & 0.72 & 0.59 & 0.63 & 0.59 & 0.52 \\
ATO1.4 & $\mathbf{0 . 9 5}$ & 0.69 & 0.56 & 0.68 & 0.64 & 0.48 \\
ATB1.1 & 0.77 & $\mathbf{0 . 8 4}$ & 0.54 & 0.53 & 0.46 & 0.36 \\
ATB1.2 & 0.55 & $\mathbf{0 . 8 8}$ & 0.74 & 0.38 & 0.40 & 0.40 \\
ATB1.3 & 0.65 & $\mathbf{0 . 8 9}$ & 0.73 & 0.46 & 0.44 & 0.43 \\
ATB1.4 & 0.65 & $\mathbf{0 . 8 8}$ & 0.74 & 0.45 & 0.45 & 0.50 \\
BI1.1 & 0.51 & 0.73 & $\mathbf{0 . 9 1}$ & 0.43 & 0.43 & 0.51 \\
BI1.2 & 0.58 & 0.73 & $\mathbf{0 . 9 3}$ & 0.42 & 0.41 & 0.56 \\
ATO2.1 & 0.60 & 0.46 & 0.42 & $\mathbf{0 . 9 2}$ & 0.77 & 0.60 \\
ATO2.2 & 0.67 & 0.52 & 0.45 & $\mathbf{0 . 9 5}$ & 0.84 & 0.61 \\
ATO2.3 & 0.66 & 0.51 & 0.42 & $\mathbf{0 . 9 3}$ & 0.83 & 0.57 \\
ATO2.4 & 0.67 & 0.49 & 0.46 & $\mathbf{0 . 9 6}$ & 0.81 & 0.60 \\
ATB2.1 & 0.60 & 0.48 & 0.42 & 0.82 & $\mathbf{0 . 9 2}$ & 0.63 \\
ATB2.2 & 0.55 & 0.47 & 0.45 & 0.73 & $\mathbf{0 . 8 9}$ & 0.68 \\
ATB2.3 & 0.57 & 0.47 & 0.42 & 0.78 & $\mathbf{0 . 9 1}$ & 0.65 \\
ATB2.4 & 0.53 & 0.40 & 0.35 & 0.76 & $\mathbf{0 . 8 7}$ & 0.59 \\
BI2.1 & 0.45 & 0.46 & 0.57 & 0.58 & 0.66 & $\mathbf{0 . 9 5}$ \\
BI2.2 & 0.51 & 0.47 & 0.54 & 0.62 & 0.69 & $\mathbf{0 . 9 5}$ \\
\hline
\end{tabular}

Thompson, 1995; Chin, 1998). Confirmatory factor analysis with PLS showed that all items exhibited loadings of more than 0.70 to their corresponding constructs, indicating adequate reliability of items.

We assessed discriminant validity by examining crossloadings and the relationship between correlations among constructs and the square root of AVEs. One criterion for discriminant validity is that no measurement item should load more highly on any construct other than the construct it intends to measure (Chin, 1998). An examination of crossfactor loadings in Table 3 shows that all items satisfied this guideline. A more restrictive guideline suggests that there should be a minimum difference of .10 between item loadings and cross loadings (Gefen \& Straub, 2005). In Table 3, all but one item (ATB1.1, which has a 0.7 difference between loading on ATB1 and cross loading on ATO1) satisfies this strict guideline. 
TABLE 4. Composite reliability and correlations of constructs.

\begin{tabular}{lcccccccc}
\hline & Items \# & $\begin{array}{c}\text { Composite } \\
\text { reliability }\end{array}$ & AVE & ATO1 & ATB1 & BI1 & ATO2 & ATB2 \\
\hline ATO1 & 4 & 0.96 & 0.86 & $\mathbf{0 . 9 3}$ & & & & \\
ATB1 & 4 & 0.92 & 0.75 & 0.75 & $\mathbf{0 . 8 7}$ & & & \\
BI1 & 2 & 0.91 & 0.84 & 0.59 & 0.79 & $\mathbf{0 . 9 2}$ & & \\
ATO2 & 4 & 0.97 & 0.90 & 0.69 & 0.52 & 0.46 & $\mathbf{0 . 9 5}$ & 0.86 \\
ATB2 & 4 & 0.94 & 0.81 & 0.62 & 0.51 & 0.46 & 0.90 & 0.71 \\
BI2 & 2 & 0.95 & 0.90 & 0.50 & 0.49 & 0.58 & 0.63 & $\mathbf{0 . 9 5}$ \\
\hline
\end{tabular}

TABLE 5. Collinearity testing.

\begin{tabular}{ll|ll}
\hline Time 1 & Mean & Time 2 & Mean \\
\hline ATO1.1 & 4.229 & ATO2.1 & 3.828 \\
ATO1.2 & 5.323 & ATO2.2 & 6.025 \\
ATO1.3 & 6.598 & ATO2.3 & 6.816 \\
ATO1.4 & 4.740 & ATO2.4 & 7.244 \\
ATB1.1 & 2.147 & ATB2.1 & 3.318 \\
ATB1.2 & 5.709 & ATB2.2 & 2.794 \\
ATB1.3 & 3.964 & ATB2.3 & 1.679 \\
ATB1.4 & 4.013 & ATB2.4 & 2.377 \\
BI1.1 & 2.297 & BI2.1 & 1.754 \\
BI1.2 & 2.297 & BI2.2 & 1.754 \\
\hline
\end{tabular}

Table 4 shows composite reliability and AVE calculated by PLS. AVE measures the amount of variance that a construct captures from its indicators relative to the amount due to measurement error (Chin, 1998). It is recommended to exceed 0.5. As shown in Table 4, all of the constructs met this guideline. AVE is also suggested to serve as a means of evaluating discriminant validity (Fornell \& Larcker, 1981). The square root of the AVEs should be larger than the correlations among the constructs (Gefen \& Straub, 2005). This indicates that more variance is shared between the construct and its indicators than with other constructs. In Table 4, the shaded numbers on the leading diagonals are the square roots of the AVEs. Offdiagonal elements are the correlations among constructs. All diagonal numbers are greater than the off diagonal ones.

\section{Structural Model Testing}

Our first step in testing the structural model is to check the presence of multicollinearity, given some of the high cross-loadings we observe in Table 3 and high inter-construct correlations in Table 4. Specifically, we checked the varianceinflation factor (VIF) for each factor in the model. Table 5 shows the results. As we can see, all VIF statistics are well below the commonly accepted threshold of 10 (Hair, Black, Babin, Anderson, \& Thatham, 2005). Therefore, we conclude that multicollinearity is not a problem for our analysis.

To answer RQ1 (H1-H3), the generic relationships among ATO, ATB, and BI, we first tested two independent models that contain ATO1-ATB1-BI1 and ATO2-ATB2-BI2 respectively. Figures $2 \mathrm{a}$ and $2 \mathrm{~b}$ show the results. Although the coefficients and $\mathrm{R}$ squares are slightly different, the relationships are at the same significant levels.

To test whether ATB fully mediates ATO's effect on BI, we conducted a three-step analysis as suggested by (Baron \& Kenny, 1986). Specifically, three steps are needed to test a mediating effect of the mediator $(\mathrm{z})$ on the relationship between the independent variable (x) and dependent variable (y): (a), $x$ has a significant impact on y; (b) $\mathrm{z}$ has a significant impact on y; and (c) x's impact on y is weakened (partial mediation) or even non-significant (full mediation) when $\mathrm{z}$ is present as the mediator.

We first tested the mediating effects in the full model. When ATB1 and ATB2 are not considered, ATO1 has a significant direct effect on BI1 with a coefficient of $0.59(p<0.001)$ and ATO2 has a significant direct effect on BI2 with a coefficient of 0.46. In the full model where ATB1 and ATB2 are present, the links between ATO1 and BI1 and ATO2 and BI2 are non-significant and the links for ATB1->BI and ATB2-> $\mathrm{BI} 2$ are significant (both $\mathrm{p}<0.001$ ), meaning that ATB1 fully mediates the effect ATO1 has on BI1 and ATB2 fully mediates the effect of ATO2 on BI2.

We also tested the mediating effect of ATB independently for initial and continued use. At Time 1, ATO1 and BI1 is significantly correlated when ATB 1 is absent $(b=0.60$, $p<.001)$. The same is true for Time 2: ATO2->BI2 is significant $(\mathrm{b}=0.63, p<.001)$ when ATB2 is absent. Combined with the results in Figures $2 a$ and $2 b$, we can conclude that at any given time of ICT use, ATB fully mediates ATO's effect on BI.

Our data indicate that when ATO, ATB, and BI are measured at the same time and are all considered in a model, there are generic relationships among them regardless of ICT use stages: ATO influences ATB, and ATO influences BI fully through ATB. Although we have only two sets of data representing two time points, we believe that such a generic model exists at any ICT use stage, as predicted by attitude theories (Ajzen \& Fishbein, 2005).

To test other hypotheses and further test H1-3 in light of other relationships, we tested a structural model that summarizes all the hypotheses, as shown in Figure 3. PLS does not use model fit indices; however, the explanatory power of a structural model could be assessed by the $\mathrm{R}$ square values (variance accounted for) in the dependent latent variables. Figure 3 shows that the model explains $58 \%$ of the variance 
(a)

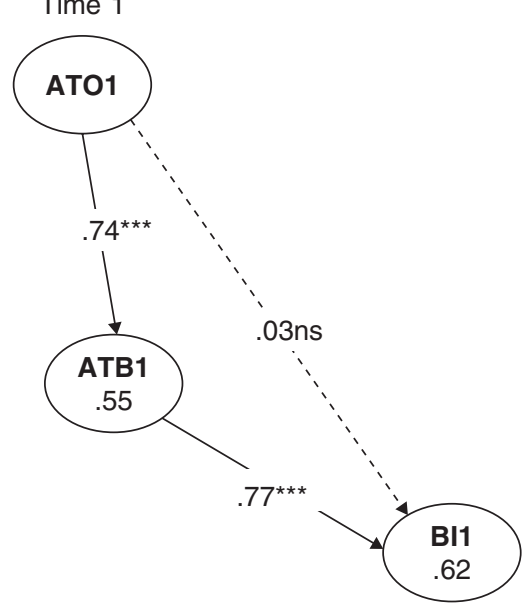

(b) Time 2

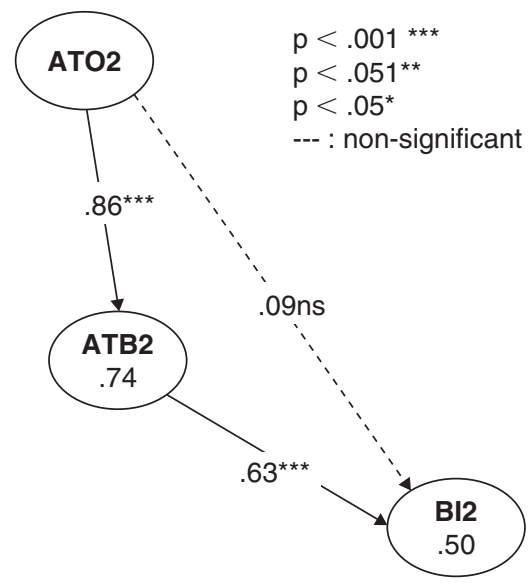

FIG. 2. (a) The Generic Model (Time 1); (b) The Generic Model at Time 2.

in $\mathrm{BI} 2,75 \%$ in $\mathrm{ATB} 2,48 \%$ in $\mathrm{ATO} 2,63 \%$ in BI1, and $57 \%$ in ATB1.

Table 6 summarizes the hypotheses testing results. Except H5, all excepted relationships are supported by the empirical data. Attitude toward object can be "transferred" or
TABLE 6. Summary of hypotheses support.

\begin{tabular}{llcc}
\hline ID & Hypotheses & $\begin{array}{c}\text { Expected } \\
\text { result }\end{array}$ & $\begin{array}{c}\text { Expectations } \\
\text { confirmed? }\end{array}$ \\
\hline $1 \mathrm{a}$ & ATO1->ATB1 & Yes & $\sqrt{ }$ \\
$1 \mathrm{~b}$ & ATO2->ATB2 & Yes & $\sqrt{ }$ \\
$2 \mathrm{a}$ & ATB1->BI1 & Yes & $\sqrt{ }$ \\
$2 \mathrm{~b}$ & ATB2->B12 & Yes & $\sqrt{ }$ \\
$3 \mathrm{a}$ & ATO1->BI1 & No & $\sqrt{ }$ \\
$3 \mathrm{~b}$ & ATO2->BI2 & No & $\sqrt{ }$ \\
4 & ATO1->ATO2 & Yes & $\sqrt{ }$ \\
5 & ATB1->ATB2 & Yes & $\times$ \\
6 & ATO1->ATB2 & No & $\sqrt{ }$ \\
7 & ATB1->ATO2 & No & $\sqrt{ }$ \\
8 & BI1->BI2 & Yes & $\sqrt{ }$ \\
\hline
\end{tabular}

"carried over" through time (H4), but not attitude toward behavior (H5).

\section{Post-Hoc Analyses: Illustrations of False Exclusions in Existing Studies}

The results of the structural model can shed light on prior empirical studies using longitudinal data. Specifically, ATO or ATB (but few studies considered both) are considered as independent variables and are measured at a different (early) time than the dependent variable BI. The main reason for such a design is to avoid the common method bias (Podsakoff, MacKenzie, Lee, \& Podsakoff, 2003). However, this design can also have the drawback of a false exclusion. We, thus, conduct a post hoc analysis to illustrate this drawback.

We tested a model in which only ATO1 and BI2, or only ATB1 and BI2, are considered. That is, we wanted to see whether early attitudes ATO1 or ATB1 can predict later intention BI2 if they are the only variables in a model, as many researchers have done. The results are depicted in Figure 4a. It shows that both ATO1 and ATB1 can have a significant effect on BI2 with R squares between 0.24-0.26. This means that the two attitudes that are measured during an early time

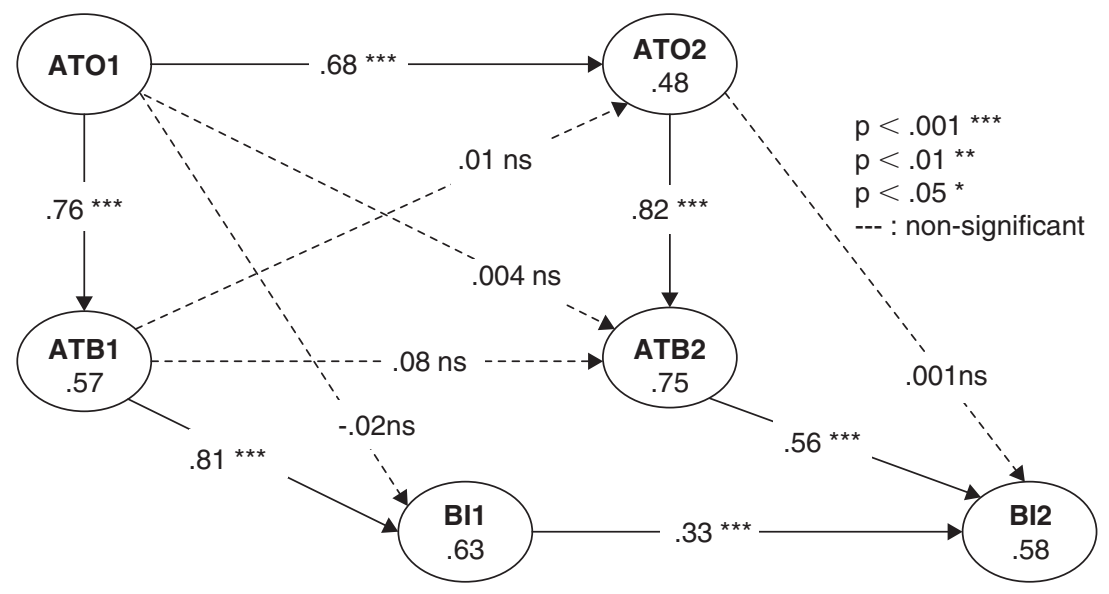

FIG. 3. The Empirical Model. 
(a)

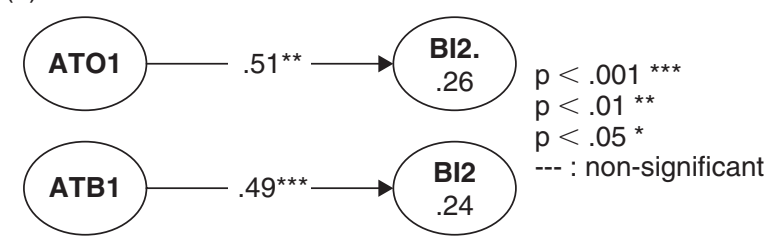

(b)

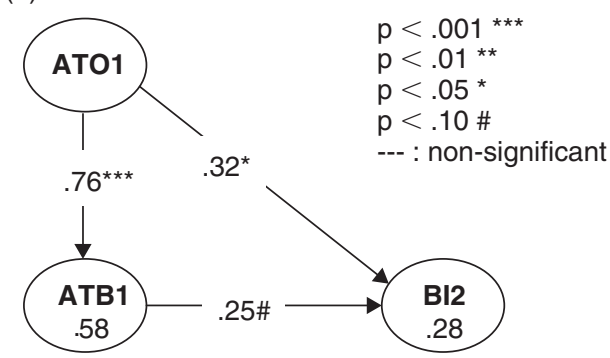

FIG. 4. (a) ATO1 or ATB1's Effect on BI2. (b) ATO1 and ATB1's Effects on BI2.

could directly influence BI measured at a later time when only these variables are considered and that ATB's effect is slightly weaker than ATO's. To continue to explore the possibility of having both ATO1 and ATB1 in the same model with BI2 (as in a study where ATO is defined as satisfaction), we ran another model involving both ATO1 and ATB1 and BI2 (Figure 4b). We found that ATO1->BI2 is significant, yet ATB1->BI2 is barely significant, and the R square is a little better than those in Figure 4a.

Together, we can conclude that the partial models as depicted in Figure $4 \mathrm{a}$ and $4 \mathrm{~b}$ can be misleading. Specifically, without considering the current attitudes (mediators), there could be two misleading messages in such findings. First, early attitudes show significant influence on the current BI, but with much smaller R squares. This may mislead researchers to believe the small effects or research power of attitudes in general (Type I error). This may be one reason why several prior studies found a non-significant impact of attitude on BI. Second, without considering the current attitudes, ATO's effect is almost the same if not much larger than ATB's, which may mislead researchers to believe that ATO is equally or even more important (as in the case of Figure 4b) in predicting BI than ATB is.

\section{Conclusions}

\section{Limitations of the Study}

Before we discuss our findings and their implications, it is important to realize the limitations of this study. First, our findings are based on the mandatory ICT use situation. Thus, they should be applied or interpreted with caution. Second, we did not consider or control for many other pertinent factors that are known to influence attitudes. This is a trade-off between being comprehensive and being more focused or parsimonious. We decided to be more focused on understanding the dynamics of attitudes. Future research may take into account other factors in the TRA model, such as subjective norms and beliefs, probably as control variables to get a better understanding of the constructs in the current model.

Third, other limitations include the relatively high correlations and high cross-loadings, indicating that the discriminant validities of the constructs in the research model could be concern. Table 3 and Table 4 show the high cross-loadings and correlations, respectively, especially for ATO and ATB as well as their items. Nevertheless, although acknowledging the statistics may show that the discriminant validity of the constructs in the research model could be a concern, we do think the discriminant validities are in general still acceptable, statistics wise, for the following reasons.

First, all items loaded more highly on their construct than they loaded on any other construct, and, in all cases, among the cross loadings the differences were greater than 0.10. Therefore, the cross-loadings are indeed acceptable. Second, the other test, the comparison of square roots of AVEs and correlations as in Table 4 shows satisfying discriminant validity, which enhances our confidence in the acceptability of the discriminant validity of the constructs in the research model. Finally, we were not surprised to learn the high cross-loadings, in light of the fact that the constructs, primarily attitudinal and intentional, are conceptually and empirically closely related. One of the major theoretical contributions of this research is to distinguish the subtle differences among these constructs. The conceptual closeness of ATO and ATB can be further supported by prior empirical studies. For instance, Wixom and Podd's (2005) empirical study showed that behavioral attitude (ATB) is highly correlated with object-based attitudes including information satisfaction $(r=0.73)$ and system satisfaction $(r=0.84)$. This confirms the empirical similarity between these two concepts. We, thus, believe that the high correlations between ATO and ATB are not from the research design of this research. That said, we do remind researchers of this limitation with regard to the discriminant validity. Further research to address this issue is desired.

Finally, the 8-week interval between the two points of time may not be long enough for the continued use to fully enfold. We measured the initial use 4 weeks after the semester started, rendering the students sufficient time to try out the new system. This, however, does not leave sufficient time for us to examine the continued use because we need to finish the survey before the end of semester. A 14 week interval, as used by prior longitudinal studies (e.g., Davis et al., 1989; Taylor \& Todd, 1995), would be ideal.

\section{Theoretical Contributions}

To the best of our knowledge, this is the first study that carefully considers both types of attitudes in a longitudinal setting to investigate the longitudinal relationships among attitudes and BI in the ICT context. Our ultimate messages 
are that attitudes are complex concepts. Our understanding of attitudes has been very limited and it would be too early to claim that attitudes do not play a role in predicting ICT acceptance and use intentions. It begs for further theoretical and empirical investigations.

Our findings have theoretical implications for the relationships among attitudes and BI in the ICT context. First, as prescribed by social psychology theories, attitudes do play important roles on BI in the ICT context, both for initial use and for continued use. That is, 63\% variance in BI during the initial use and 58\% variance in BI during continued use are explained by the integrated model (Figure 3 ) and $62 \%$ and $50 \%$, respectively, in the separate models (Figures $2 \mathrm{a}$ and $2 \mathrm{~b}$ ), where attitudes are the only antecedents of BIs. This suggests that any research model that omits attitudes as antecedents of BI would miss a great part in the ICT acceptance and use phenomenon.

Second, the attitude that significantly influences BI needs to be at a particular specificity with $\mathrm{BI}$ on evaluation target and evaluation time, and time specificity can supersede target specificity.

Third, the two types of attitudes seem to have different natures and, thus, show different long-lasting effects through time. Attitude toward object seems to be more primary or basic. This evaluation is directly related to an ICT as an object. Once participants formed such evaluation at an early time, its effect stayed to some extent, or it seems that such evaluation can be "carried" over to a future time. Attitude toward using ICT, on the other hand, seems more secondary, complex, or calculative and "on the spot." This makes sense because such evaluation refers to two different concepts: one is of the ICT as an object, and the other is one's behavior on the object, which is more malleable, considering that users' evaluations of using an ICT are constantly updated. So, ATB is "difficult to carry around" and has to be calculated when asked. This speculation can explain the findings where ATB1 does not have direct effect on ATB2, nor does BI1 on ATB2. Both ATB1 and BI1 influence ATB2 fully via ATO2.

\section{Research Implications}

This study prompts several research implications. The first has to do with the operational treatment of attitudes in future empirical studies: One should pay attention to the holistic nature of attitude that includes both instrumental and experiential dimensions. Second, researchers need to pay attention to the antecedents both of ATO and of ATB because of their different impacts on BI and different long-lasting effects over time, and they need to choose explicitly which one is their focus. TRA and TPB clearly stated the importance of instrumental determinants (various beliefs). Recent movement in IS, psychology, and other fields has started to examine the experiential (largely affective) antecedents of attitudes. This makes sense because the structure of attitudes includes both components. Finally, previous empirical studies should be reexamined in light of the ATO/ATB distinction and omitting mediating variables to draw conclusions on the relationships among attitudes and BI.

\section{Practical Implications}

ATO and ATB have different characteristics and such differences can have different practical implications. Although ATO does not directly influence BI, once formed, it can have a long-lasting effect that can be carried over to late evaluations. Knowing this, practitioners such as ICT designers, managers, trainers, marketers, and other stakeholders should put energy and effort in finding ways to let users form positive attitudes at early stages. Such positive attitudes go a long way to influence the current attitudes, which are important in forming positive intentions to continuously use the target ICT.

ATB fully mediates the role of ATO on BI. Knowing this, practitioners should understand that a positive attitude toward a particular ICT will only indirectly lead potential users to decide to accept or use the ICT. To increase the chance of potential users adopting and continuously using an ICT, efforts should also be put into identifying antecedents of attitudes toward behavior in addition to attitude toward the ICT.

\section{References}

Agarwal, R., \& Prasad, J. (1997). The role of innovation characteristics and perceived voluntariness in the acceptance of information technologies. Decision Sciences, 28(3), 557.

Agarwal, R., \& Prasad, J. (1999). Are individual differences germane to the acceptance of new information technologies? Decision Sciences, 30(2), 361-391.

Ajzen, I. (1985). From intentions to actions: A theory of planned behavior. In J. Kuhl \& J. Beckmann (Eds.), Action control: From cognition to behavior (pp. 11-39). New York: Springer Verlag.

Ajzen, I. (1991). The theory of planned behavior. Organizational Behavior and Human Decision Processes, 50(2), 179-211.

Ajzen, I., \& Fishbein, M. (1980). Understanding attitudes and predicting social behavior. Englewood Cliffs, NJ: Prentice-Hall.

Ajzen, I., \& Fishbein, M. (2005). The influence of attitudes on behavior. In D. Albarracin, B.T. Johnson, \& M.P. Zanna (Eds.), Handbook of attitudes and attitude change. Mahwah, NJ: Lawrence Erlbaum Associates.

Albarracin, D., Zanna, M.P., Johnson, B.T., \& Kumkale, G.T. (2005). Attitudes: Introduction and scope. In D. Albarracin, B.T. Johnson, \& M.P. Zanna (Eds.), The handbook of attitudes (pp. 3-19). Mahwah, New Jersey: Lawrence Erlbaum Associates.

Bamberg, S., Ajzen, I., \& Schmidt, P. (2003). Choice of travel mode in the theory of planned behavior: The roles of past behavior, habit, and reasoned action. Basic and Applied Social Psychology, 25(3), 175-187.

Barclay, D., Higgins, C., \& Thompson, R. (1995). The partial least squares (PLS) approach to causal modeling, personal computer adoption and use as an illustration. Technology Studies, 2(2), 285-309.

Barki, H., \& Hartwick, J. (1989). Rethinking the concept of user involvement. MIS Quarterly, 13(1), 53-63.

Barki, H., \& Hartwick, J. (1994). Measuring user participation, use involvement, and user attitude. MIS Quarterly, 18(1), 59-82.

Baron, R.M., \& Kenny, D.A. (1986). The moderator-mediator distinction in social psychology research: Conceptual, strategic, and statistical considerations. Journal of Personality and Social Psychology, 51, 1173-1183.

Bhattacherjee, A., \& Premkumar, G. (2004). Understanding changes in belief and attitude toward information technology usage: A theoretical model and longitudinal test. MIS Quarterly, 28(2), 229-254. 
Bhattacherjee, A., \& Sanford, C. (2006). Influence processes for information technology acceptance: An Elaboration likelihood model. MIS Quarterly, 30(4), 805-826.

Brown, S.A., Fuller, R.M., \& Vician, C. (2004). Who's afraid of the virtual world? Anxiety and computer-mediated communication. Journal of the Association for Information Systems, 5(2), 79-107.

Chau, P.Y.K., \& Hu, P.J.H. (2001). Information technology acceptance by individual professionals: A model comparison approach. Decision Sciences, 32(4), 699-719.

Chin, W.W. (1998). The partial least squares approach to structural equation modeling. In G.A. Marcoulides (Ed.), Modern methods for business research (pp. 295-336). Mahwah, NJ: Lawrence Erlbaum Associates.

Compeau, D.R., \& Higgins, C.A. (1995). Computer self efficacy: Development of a measure and initial test. MIS Quarterly, 19(2), 189-211.

Compeau, D.R., Higgins, C.A., \& Huff, S.L. (1999). Social cognitive theory and individual reactions to computing technology: A longitudinal study. MIS Quarterly, 23(2), 145-158.

Crites, S.L., Jr., Fabrigar, L.R., \& Petty, R.E. (1994). Measuring the affective and cognitive properties of attitudes: Conceptual and methodological issues. Personality and Social Psychology Bulletin, 20, 619-634.

Davis, F. (1989). Perceived usefulness, perceived ease of use, and user acceptance of information technology. MIS Quarterly, 13(3), 319-340.

Davis, F.D., Bagozzi, R.P., \& Warshaw, P.R. (1989). User acceptance of computer technology: A comparison of two theoretical models. Management Science, 35(8), 982-1003.

Eagly, A.H., \& Chaiken, S. (1998). Attitude structure and function. In D.T. Gilbert, S.T. Fiske \& G. Lindzey (Eds.), The handbook of social psychology (4th ed., Vol. 1, pp. 269-322). New York: Oxford University Press.

Fishbein, M., \& Ajzen, I. (1975). Belief, attitude, intention and behavior: An introduction to theory and research. Reading, MA: Addison-Wesley.

Fishbein, M., \& Ajzen, I. (1975). Beliefs, attitude, intention and behavior: An introduction to theory and research. Reading, MA: Addison-Wesley.

Forgas, J.P. (2000). Feeling is believing? The role of processing strategies in mediating affective influences on beliefs. In N.H. Frijda, A.S.R. Manstead \& S. Bem (Eds.), Emotions and beliefs: How feelings influence thoughts (pp. 108-143). Cambridge, United Kingdom: Cambridge University Press.

Fornell, C., \& Larcker, D.F. (1981). Structural equation models with unobservable variables and measurement errors. Journal of Marketing Research, 18(2), 39-50.

Galletta, D.F., Henry, R., McCoy, S., \& Polak, P. (2004). Web site delays: How tolerant are users? Journal of the Association for Information Systems, 5(1), 1-28.

Gefen, D., \& Straub, D. (2005). A practical guide to factorial validity using PLS-graph: Tutorial and annotated example. Communications of the Association for Information Systems, 16, 91-109.

Gefen, D., Straub, D., \& Boudreau, M. (2000). Structural equation modeling and regression: guidelines for research practice. Communications of the Association for Information Systems, 4(7), 1-77.

Hair, J.F.J., Black, W.C., Babin, B.J., Anderson, R.E., \& Thatham, R.L. (2005). Multivariate data analysis (6th ed.). Upper Saddle River, NJ: Pearson Prentice Hall.

Harrison, A.W., \& Rainer R.K. Jr, (1992). The influence of individual differences on skill in end-user computing. Journal of Management Information Systems, 9(1), 93-112.

Harrison, D.A., Mykytyn, P.P., \& Riemenschneider, C.K. (1997). Executive decisions about adoption of information technology in small business: Theory and empirical test. Information Systems Research, 8(3), 171-194.

Hartwick, J., \& Barki, H. (1994). Explaining the role of user participation in information system use. Management Science, 40(4), 440-465.

Hiltz, S.R., \& Johnson, K. (1990). User satisfaction with computer-mediated communication systems. Management Science, 36(6), 739-764.

Hong, W., Thong, J.Y.L., \& Tam, K.Y. (2004a). Does animation attract online users' attention? The effects of flash on information search performance and perceptions. Information Systems Research, 15(1), 60-86.
Hong, W., Thong, J.Y.L., \& Tam, K.Y. (2004b). The effects of information format and shopping task on consumers' online shopping behavior: A cognitive fit perspective. Journal of Management Information Systems, 21(3), 149-184.

Jackson, C.M., Chow, S., \& Leitch, R.A. (1997). Toward an understanding of the BI to use an information system. Decision Sciences, 28(2), 357-389.

Karahanna, E., Straub, D.W., \& Chervany, N. (1999). Information technology adoption across time: A cross-sectional comparison of pre-adoption and post-adoption beliefs. MIS Quarterly, 23(2), 183-213.

Kim, S.S., \& Malhotra, N.K. (2005). A longitudinal model of continued IS use: An integrative view of four mechanisms underlying postadoption phenomena. Management Science, 51(5), 741-755.

King, W.R., \& He, J. (2006). A meta-analysis of the technology acceptance model Information \& Management, 43(6), 740-755.

Lee, Y., Kozar, K.A., \& Larsen, K.R.T. (2003). The technology acceptance model: Past, present, and future. Communication of the AIS, 12(50), 752-780.

Limayem, M., \& Hirt, S.G. (2003). Force of habit and information systems usage: Theory and initial validation. Journal of Association for Information Systems, 4(3), 65-97.

Lin, C.-P., \& Bhattacherjee, A. (in press). Extending technology usage models to interactive hedonic technologies: A theoretical model and empirical test. Information Systems Journal.

Malhotra, Y., \& Galletta, D.F. (2005). A multidimensional commitment model of volitional systems adoption and usage behavior. Journal of Management Information Systems, 22(1), 117-151.

Mathieson, K. (1991). Predicting user intentions: Comparing the technology acceptance model with the theory of planned behavior. Information Systems Research, 2(3), 173-191.

Moon, J.-W., \& Kim, Y.-G. (2001). Extending the TAM for a World-WideWeb context. Information \& Management, 38(4), 217-230.

Ouellette, J.A., \& Wood, W. (1998). Habit and intention in everyday life: The multiple processes by which past behavior predicts future behavior Psychology Bulletin, 124(1), 54-74.

Petty, R.E., \& Cacioppo, J.T. (1986). Communication and persuasion: Central and peripheral routes to attitude change. New York: Springer-Verlag. Petty, R.E., \& Wegener, D.T. (1999). The elaboration likelihood model: Current status and controversies. In S. Chaiken \& Y. Trope (Eds.), Dualprocess theories in social psychology (pp. 41-72). New York: Guilford Press

Podsakoff, P., MacKenzie, S., Lee, J., \& Podsakoff, N. (2003). Common method biases in behavioral research: A critical review of the literature and recommended remedies. Journal of Applied Psychology, 88(5), 879-903.

Rogers, E. (1995). Diffusion of innovations. New York: The Free Press.

Sambamurthy, V., \& Chin, W.W. (1994). The effects of group attitudes toward alternative GDSS designs on the decision-making performance of computer-supported groups. Decision Science, 25(2), 215-239.

Schepers, J., \& Wetzels, M. (2007). A meta-analysis of the technology acceptance model: Investigating subjective norm and moderation effects. Information \& Management, 44(1), 90-103.

Sun, H., \& Zhang, P. (2006). The role of moderating factors in user technology acceptance. International Journal of Human-Computer Studies, 64(2), 53-78

Taylor, S., \& Todd, P.A. (1995). Assessing IT usage: The role of prior experience. MIS Quarterly, 19(4), 561-570.

Taylor, S., \& Todd, P.A. (1995). Understanding information technology usage: A test of competing models. Information Systems Research, 6(2), 144-176.

Teo, H.-H., Oh, L.-B., Liu, C., \& Wei, K.-K. (2003). Effects of interactivity on Web user attitude. International Journal of Human-Computer Studies, 58(3), 281-305.

Thompson, R.L., \& Higgins, C.A. (1994). Influence of experience on personal computer utilization: Testing a conceptual model. Journal of Management Information Systems, 11(1), 167-187.

Thompson, R.L., Higgins, C.A., \& Howell, J.M. (1991). Personal computing toward a conceptual model of utilization. MIS Quarterly, 15(1), 125-136. 
Venkatesh, V., \& Davis, F. (2000). A theoretical extension of the technology acceptance model: Four longitudinal field studies. Management Science, 46(2), 186-204.

Venkatesh, V., Morris, M.G., Davis, G.B., \& Davis, F.D. (2003). User acceptance of information technology: Toward a unified view. MIS Quarterly, 27(3), 425-478.

Webster, J., \& Martocchio, J.J. (1992). Microcomputer playfulness: Development of a measure with workplace implications. MIS Quarterly, 16(1).

Wegener, D.T., \& Carlston, D.E. (2005). Cognitive processes in attitude formation and change. In D. Albarracín, B.T. Johnson \& M.P. Zanna (Eds.), The handbook of attitudes (pp. 493-542). Mahwah, NJ: Lawrence Erlbaum Associates.
Wixom, B.H., \& Todd, P. (2005). A theoretical integration of user satisfaction and technology acceptance. Information Systems Research, 16(1), 85-102.

Wixom, B.H., \& Todd, P.A. (2005). A theoretical integration of user satisfaction and technology acceptance. Information Systems Research, 16(1), 85-102.

Yang, H.D., \& Yoo, Y. (2004). It's all about attitude: Revisiting the technology acceptance model. Decision Support Systems, 38, 19-31.

Zhang, P., Aikman, S., \& Sun, H. (2008). Two types of attitudes in ICT acceptance and use. International Journal of Human Computer Interaction, 24(7), 1-21. 


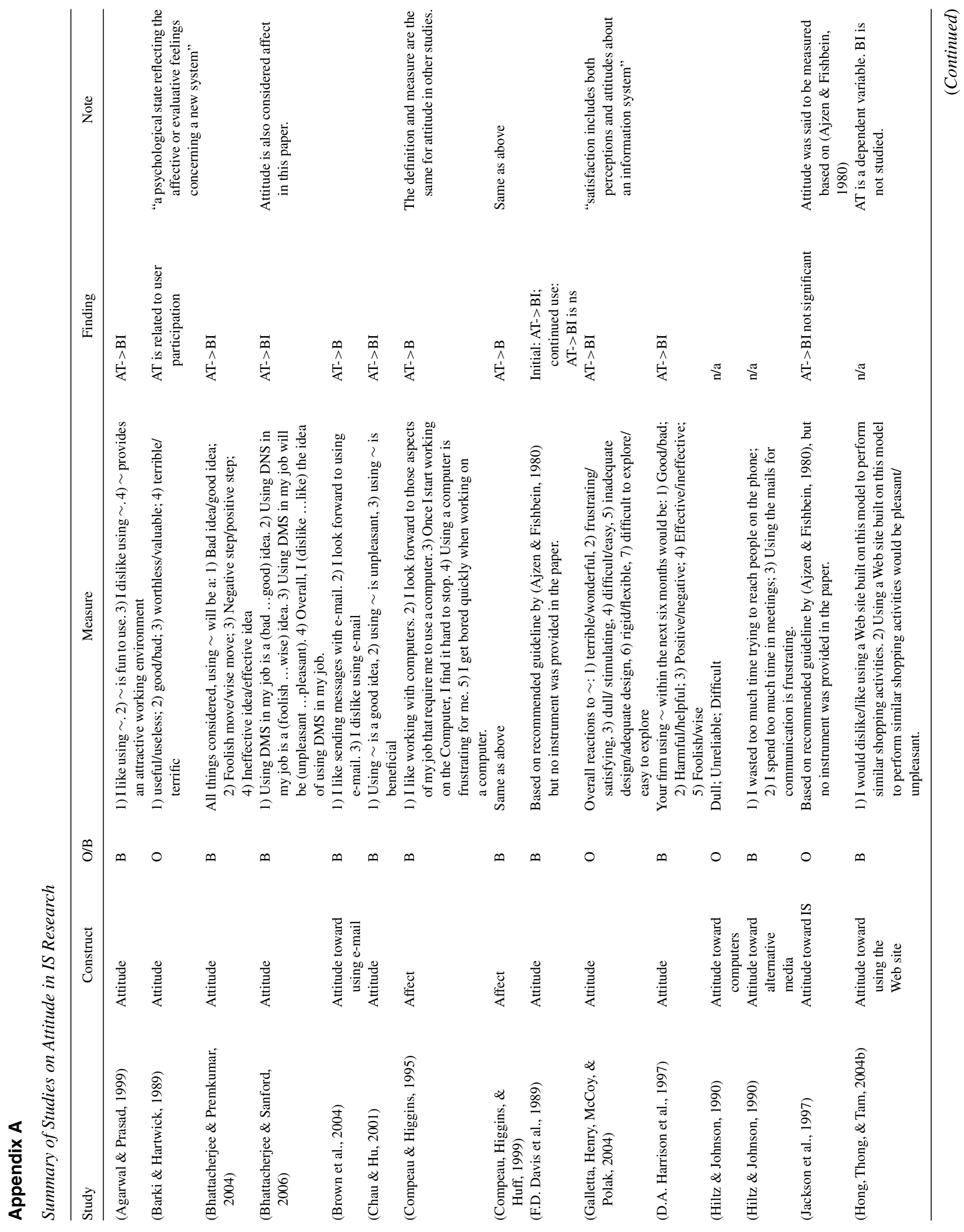




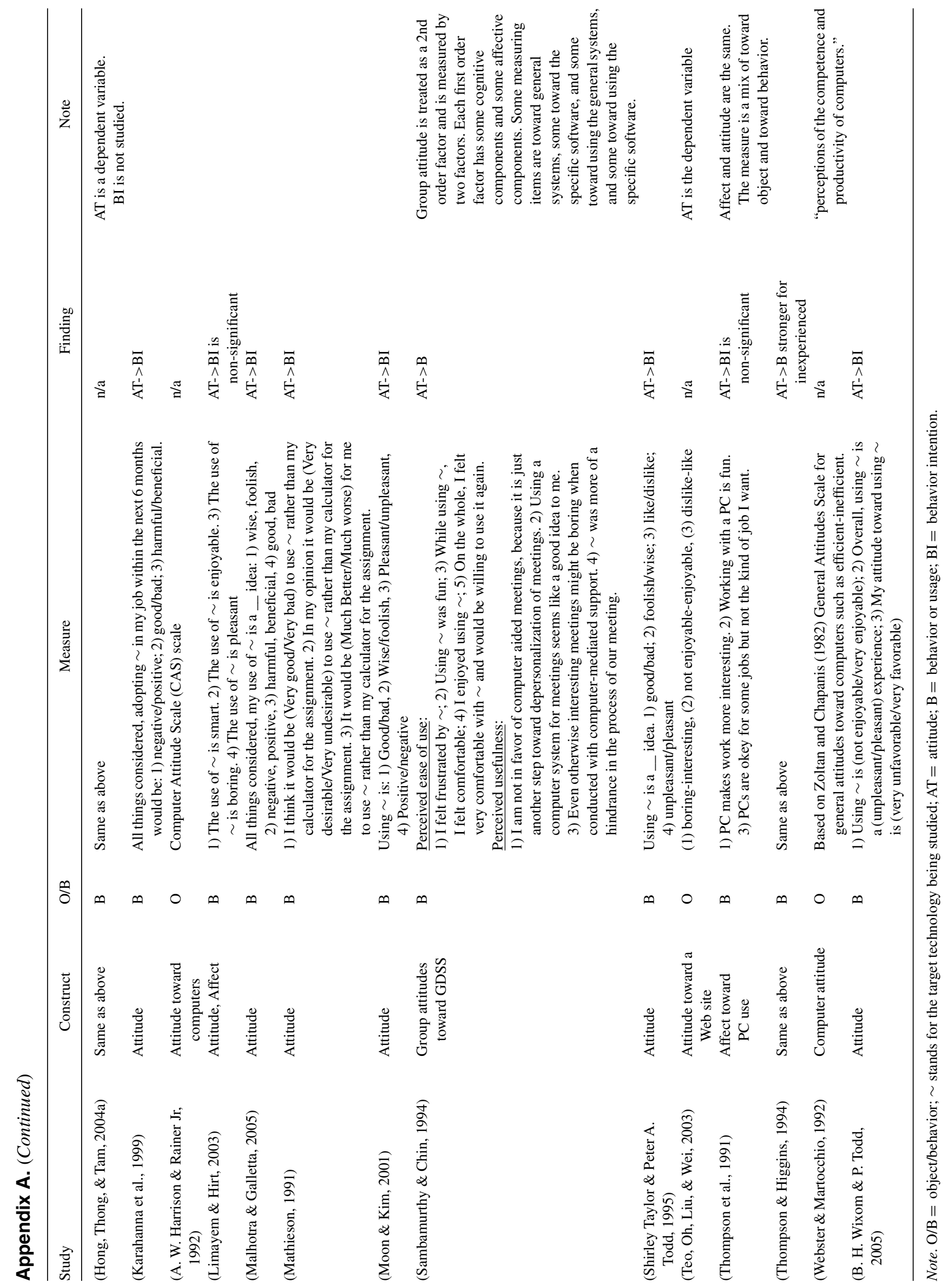




\section{Appendix B}

\section{The Instrument}

\begin{tabular}{|c|c|c|c|}
\hline \multicolumn{2}{|r|}{ Attitude toward object (ATO) } & \multicolumn{2}{|c|}{ Attitude toward behavior (ATB) } \\
\hline ATO.1 & I think WebCT 6 is desirable & ATB.1 & Using WebCT 6 is pleasant \\
\hline ATO.2 & I like WebCT 6 & АТВ. 2 & Using WebCT 6 is valuable \\
\hline ATO.3 & In general, I am positive about WebCT 6 & ATB. 3 & Using WebCT 6 is desirable \\
\hline ATO. 4 & In general, WebCT 6 is good & ATB. 4 & Using WebCT 6 is interesting \\
\hline
\end{tabular}

$\mathrm{BI}(\mathrm{BI})$

BI.1

I intend to use WebCT 6 at every opportunity in the future

BI.2 I plan to increase my use of WebCT 6 in the future 